\title{
Rewarding Effects and Reinstatement of MDMA-Induced CPP in Adolescent Mice
}

\author{
Manuel Daza-Losada', Bruno Ribeiro Do Couto', Carmen Manzanedo², Maria A Aguilar', \\ Marta Rodríguez-Arias' and Jose Miñarro*,I \\ 'Facultad de Psicología, Departamento de Psicobiología, Unidad de Investigación Psicobiología de las Drogodependencias, Universitat de \\ Valencia, Valencia, Spain; ²Departamento de Anatomía Humana y Psicobiología, Universidad de Murcia, Campus de Espinardo, Murcia, Spain
}

\begin{abstract}
Although the rewarding effects of 3,4-methylenedioxy-metamphetamine (MDMA) have been demonstrated in self-administration and conditioned place preference (CPP) procedures, its addictive potential (ie, the vulnerability to relapse, measured by its ability to induce reinstatement of an extinguished response), remains poorly understood. In this study, the effects of MDMA (5, 10 , and $20 \mathrm{mg} / \mathrm{kg}$ ) on the acquisition, extinction and reinstatement of CPP were evaluated in mice, using two different protocols during acquisition of CPP. In the first experiment, animals were trained using a two-session/day schedule (MDMA and saline for 4 consecutive days), whereas in the second experiment, they were trained using an alternating day schedule (MDMA and saline each $48 \mathrm{~h}$ ). After extinction, the ability of drug priming to reinstate CPP was evaluated. In Experiment I, MDMA did not significantly increase the time spent in the drug-paired compartment during the post-conditioning (Post-C) test, although the preference was evident a week afterwards, lasting between 2 and 21 weeks. No reinstatement was observed after MDMA priming. In Experiment 2, all doses produced CPP in Post-C, which lasted between I and 4 weeks. MDMA induces reinstatement at doses up to 4 times lower than those used in conditioning. The analyses of brain monoamines revealed that the daily schedule of treatment induces a non-dose-dependent decrease in dopamine and serotonin $(5-\mathrm{HT})$ in the striatum, whereas the alternating schedule produces a dose-dependent decrease of $5-\mathrm{HT}$ in the cortex. These results demonstrate that MDMA produces long-lasting rewarding effects and reinstatement after extinction, suggesting the susceptibility of this drug to induce addiction.

Neuropsychopharmacology (2007) 32, 1750-1759; doi:I0. I038/sj.npp. I 301309; published online I4 February 2007
\end{abstract}

Keywords: MDMA; conditioned place preference; reinstatement; mice; dopamine; serotonin

\section{INTRODUCTION}

The illicit drug MDMA (3,4-methylenedioxy-metamphetamine), known on the street as 'Ecstasy', is a substituted amphetamine with euphoric and 'entactogenic' properties, including pleasant feelings, such as reduced anxiety, increased readiness to communicate, and lowered defensiveness (Nichols, 1986). Acute effects also include hyperactivity, mental perspicacity and reduced fatigue. These properties are probably the reason for the increasing use of MDMA in the last 15 years, especially in adolescent and young-adult populations during 'raves' or night parties, it currently being one of the most popular drugs of abuse in Europe (Cole and Sumnall, 2003).

MDMA induces the presynaptic release of dopamine (DA) and serotonin (5-HT) in rats (Gough et al, 1991; Hiramatsu

*Correspondence: Dr J Miñarro, Facultad de Psicología, Departamento de Psicobiología, Universitat de Valencia, Avda. Blasco Ibáñez, 2I, 46010 Valencia, Spain, Tel: + 349638640 20, Fax: + 349638646 68, E-mail: jose.minarro@uv.es

Received 10 August 2006; revised 31 October 2006; accepted 14 November 2006 and Cho, 1990; Kankaanpaa et al, 1998; Koch and Galloway, 1997; Schmidt et al, 1987; Yamamoto and Spanos, 1988) and raises extracellular DA and 5-HT in the nucleus accumbens (Nacc) (Kankaanpaa et al, 1998; O'Shea et al, 2005; White et al, 1994), increasing preferentially DA transmission in the shell compared to the core of Nacc (Cadoni et al, 2005). MDMA also produces a stimulatory effect on the release of acetylcholine in the rat prefrontal cortex, striatum, and dorsal hippocampus (Acquas et al, 2001; Nair and Gudelsky, 2006). After the initial increase in synaptic levels of 5-HT, long-term depletions of this neurotransmitter and decreased 5 -HT transporter binding have been frequently reported in rats (Boot et al, 2002; McGregor et al, 2003; Ricaurte et al, 1985). Repeated MDMA administration also induces a sustained loss in DA, but not in 5-HT, in the mouse striatum (Colado et al, 2004; Escobedo et al, 2005; Stone et al, 1987).

Studies with experimental animals have provided evidence of the rewarding effects of MDMA in the selfadministration procedure. Primates (Beardsley et al, 1986; Fantegrossi et al, 2002, 2004; Lamb and Griffiths, 1987; Lile et al, 2005), rats (Braida and Sala, 2002; Braida et al, 2005; Cornish et al, 2003; Daniela et al, 2004; Schenk et al, 2003), 
and mice (Trigo et al, 2006) learn to perform an operant response to obtain an infusion of MDMA, which suggests the addictive potential of this drug.

The conditioned place preference (CPP) paradigm is a relatively simple model that has been used to assess the affective or appetitive properties of drugs. This procedure is based on the fact that the pairing of neutral distinctive environmental stimuli with a drug (primary reward) results in an acquired preference for those specific stimuli (secondary or conditioned reward). The administration of MDMA produces CPP in rats (Bilsky and Reid, 1991; Bilsky et al, 1990, 1991, 1998; Braida et al, 2005; Cole et al, 2003; Herzig et al, 2005; Marona-Lewicka et al, 1996; Meyer et al, 2002; Schechter, 1991) and mice (Robledo et al, 2004a, b; Salzmann et al, 2003).

As commented previously, the rewarding effects of MDMA have been repeatedly demonstrated (for a review, see Cole and Sumnall, 2003), however, the addictive potential of this drug remains poorly understood. Drug addiction can be considered as a chronic disorder characterized by relapse. Craving is a subjective feeling experienced by human drug addicts, which motivates them to seek the drug and can produce relapse (O'Brien, 1997). In laboratory animals, it is very difficult to evaluate craving but it is possible to measure relapse directly if after the acquisition and subsequent extinction of a particular behavioral response (eg, pressing a lever to obtain a drug injection) the animal reinitiates this response, often referred to as reinstatement (Carroll and Comer, 1996). This recovery of the learned response seems to reflect the re-induction of craving, leading to drug seeking following a period of extinction of drug use. The paradigm of CPP has been used recently to study the relapse phenomenon in animals. In this procedure, animals are first trained to acquire a CPP, which afterwards is extinguished by exposing the subjects to the previously drug-paired compartment in the absence of the drug. It has been observed that the same stimuli that reinstate self-administration are capable of inducing the reinstatement of CPP. The most important environmental events that may lead to reinstatement are re-exposure to the drug itself, presentation of drug-associated stimuli or cues and exposure to a stressful event (Maldonado et al, 2006; Ribeiro Do Couto et al, 2005a, b; Ribeiro Do Couto et al, 2006; for a review, see Shalev et al, 2002; Shaham et al, 2003; Weiss, 2005).

The present study is the first to consider the long-term effects of MDMA on the extinction and reinstatement of CPP in adolescent mice. Taking into account the influence that the schedule used in the place conditioning procedure could have on the acquisition of CPP, we performed two separate experiments using two different protocols during acquisition of place conditioning. In the first experiment, animals were trained using a two-session/day schedule during acquisition (MDMA and saline were administered the same day for 4 consecutive days) during the conditioning phase of CPP, whereas in the second experiment they were trained using an alternating day schedule (four injections of MDMA and saline administered each $48 \mathrm{~h}$ ). There was no other difference in experimental procedures. After the acquisition of MDMA-induced CPP, all animals underwent extinction sessions until the CPP was extinguished and, afterwards, the reinstating effects of the reexposure to MDMA were evaluated.

\section{MATERIALS AND METHODS}

\section{Subjects}

A total of 200 male mice of the OF1 strain, 21 days of age, acquired commercially from Charles River (Barcelona, Spain) were used. They were housed in groups of four in plastic cages $(25 \times 25 \times 14.5 \mathrm{~cm}) 5$ days before experiments under the following conditions: constant temperature $\left(21 \pm 2{ }^{\circ} \mathrm{C}\right)$, a reversed light schedule (white lights on: 19.30-07.30 h), and food and water available ad libitum, except during behavioral tests. Animals were handled for 2 days before the pre-conditioning (Pre-C) phase to reduce their stress levels in response to experimental manipulations. Procedures involving mice and their care were conducted in conformity with national, regional and local laws and regulations, which are in accordance with the European Communities Council Directives (86/609/EEC, 24 November 1986).

\section{Apparatus}

For place conditioning, eight identical Plexiglas boxes with two equal size compartments $(30.7 \mathrm{~cm}$ length $\times 31.5 \mathrm{~cm}$ width $\times 34.5 \mathrm{~cm}$ height) separated by a gray central area $(13.8 \mathrm{~cm}$, length $\times 31.5 \mathrm{~cm}$, width $\times 34.5 \mathrm{~cm}$ height $)$ were used. The compartments have different colored walls (black $v s$ white) and also distinct floor textures (fine grid in the black compartment and wide grid in the white one). Four infrared light beams in each compartment of the box and six in the central area allowed the recording of the position of the animal and its crossings from one compartment to the other. The equipment was controlled by two IBM PC computers using MONPRE $2 \mathrm{Z}$ software (CIBERTEC, SA, Spain).

\section{Drugs}

Animals were injected i.p. with 5,10 , or $20 \mathrm{mg} / \mathrm{kg}$ of MDMA ( $\pm 3,4$-methylenedioxymetamphetamine hydrochloride, Laboratorios Sigma-Aldrich, Spain), in a volume of $0.01 \mathrm{ml} /$ g. Control groups were injected with physiological saline $(\mathrm{NaCl} 0.9 \%)$, also used to dissolve the drugs.

\section{Procedure of CPP}

Acquisition. The place conditioning, consisting of three phases, was carried out during the dark cycle following a procedure unbiased in terms of initial spontaneous preference (for more details see Manzanedo et al, 2001). During the first phase or pre-conditioning (Pre-C) mice were given access to both compartments of the apparatus for $15 \mathrm{~min}$ (900 s) each day for 3 days. On day 3, the time spent by the animal in each compartment was recorded for $900 \mathrm{~s}$. A total of 25 animals showing strong unconditioned aversion $(<33 \%$ of the session time) or preference $(>67 \%)$ for any compartment were discarded. In each group, half the animals received the drug or vehicle in one compartment and the other half in the other compartment. After assigning the compartments, an ANOVA showed that there were no significant differences between time spent in the drug-paired and the vehicle-paired compartments during 
the Pre-C phase. In the second phase (conditioning), animals were conditioned with MDMA or saline through four pairings with the respective compartment. In Experiment 1, animals received two pairings each day: animals conditioned with MDMA received an injection of physiological saline before being confined to the vehicle-paired compartment for $30 \mathrm{~min}$, and after an interval of $4 \mathrm{~h}$, received MDMA immediately before confinement in the drug-paired compartment for $30 \mathrm{~min}$; control animals received an injection of physiological saline before being confined for $30 \mathrm{~min}$ to first one compartment and then $30 \mathrm{~min}$ to the other, there being an interval of $4 \mathrm{~h}$ between each confinement (days 4-7, PN days 30-33). In Experiment 2, mice received only one pairing each day: animals conditioned with MDMA received an injection of MDMA immediately before confinement in the drug-paired compartment for $30 \mathrm{~min}$ on days $4,6,8$, and 10 (PN days 30,32 , 34 , and 36) and received physiological saline before being confined to the vehicle-paired compartment for $30 \mathrm{~min}$ on days $5,7,9$, and 11; control animals received an injection of physiological saline before being confined for $30 \mathrm{~min}$ to first one compartment on days $4,6,8$, and 10 and then $30 \mathrm{~min}$ to the other on days $5,7,9$, and 11 . The central area was never used during conditioning and was blocked by guillotine doors. During the third phase or post-conditioning (Post-C), on day 8 (Experiment 1) or 12 (Experiment 2), the guillotine doors separating the two compartments were removed and the time spent by the untreated mice in each compartment was recorded during $900 \mathrm{~s}$ of observation (Post-C tests were performed between 1000 and 1400 hours). The difference in seconds between the time spent in the drug-paired compartment in the Post- $C$ test and that spent in the Pre-C test is a measure of the degree of conditioning induced by the drug. If this difference is positive then the drug has induced a preference for the drug-paired compartment, whereas the opposite indicates the induction of an aversion.

Extinction: Control and MDMA-conditioned groups underwent a weekly extinction session which consisted of the placement of animals in the apparatus (without guillotine doors separating the compartments) for $15 \mathrm{~min}$ until the time spent in the drug-paired compartment for each group conditioned with MDMA was similar to those of Pre-C. Thus, in each group, all the animals received the same number of extinction sessions, independently of their individual scores, as the criterion of extinction was a lack of significant differences with respect to Pre-C values. Salineconditioned groups only performed one extinction session to confirm the lack of CPP. The extinction of CPP was always confirmed in a subsequent session performed $48 \mathrm{~h}$ after the last extinction session. A weekly extinction was chosen on the basis of a previous study that used this schedule to evaluate drug-priming reinstatement of D-methamphetamine CPP (Li et al, 2002).

Reinstatement: The effects of a priming dose of MDMA were evaluated $48 \mathrm{~h}$ after the confirmation of extinction. The tests of reinstatement (performed between 1000 and 1400 hours) were the same as for Post-C (free ambulation for $15 \mathrm{~min}$ ) except that animals were tested $15 \mathrm{~min}$ after the administration of the respective dose of MDMA.
Analysis of biogenic amines: Eight separate groups of animals received the same schedules of treatment as in the first and second experiment, that is, four daily consecutive injections (daily schedule of treatment) or four injections on alternating days (intermittent schedule) of saline, 5, 10, or $20 \mathrm{mg} / \mathrm{kg}$ of MDMA. At the corresponding time of test, 24 (daily schedule) or 48 (intermittent schedule) $\mathrm{h}$ after the last injection, mice were killed by cervical fracture. Within 2 min their brains were removed and placed on an ice-cold plate. The striatum, cortex, and hippocampus were dissected out, frozen on dry ice and stored at $-80^{\circ} \mathrm{C}$. The tissue was thawed, weighed and then, homogenized in $200 \mu \mathrm{l}$ of perchloric acid $(0.1 \mathrm{~N})$ using ultrasounds. The homogenate was centrifuged at 14000 r.p.m. for $30 \mathrm{~min}$. The supernatant was divided into aliquots for the analysis of biogenic amines. DA, dihydroxyphenyl acetic acid (DOPAC), homovanilic acid (HVA), 5-HT, and 5-hidroxyindole acetic acid (5-HIAA) were analyzed in a high performance liquid chromatograph (Agilent 1100 series HPLC). Samples were applied to a column $(0.5 \mu \mathrm{m}, 12.5 \mathrm{~cm}, 4.6 \mathrm{~cm}$; Agilent Zorbax High Pressure Cartige Guard-column). An isocratic mobile phase consisting of $0.10 \mathrm{M}$ chloroacetic acid, $0.70 \mathrm{mM}$ EDTA, $1.0 \mathrm{mM}$ sodium octysulphate ( $\mathrm{pH} 3.25)$ in $14 \%$ methanol was passed through the column at a constant flow of $1 \mathrm{ml} / \mathrm{min}$. The column was maintained at $21^{\circ} \mathrm{C}$. Analytes were oxidized on a glassy carbon electrode maintained at $300 \mathrm{mV}$ ( $450 \mathrm{mV}$ for HVA detection) against a $\mathrm{Ag} / \mathrm{AgCl}$ reference electrode (BAS). The complete separation of biogenic amines was achieved in $25 \mathrm{~min}$. Data were collected and analyzed using the Merk-Hitachi software package (Model D-7000). Levels of 5-HT and 5-HIAA were analyzed in striatum, cortex and hippocampus. Moreover, levels of DA, DOPAC, and HVA were analyzed in striatum.

Statistical analysis: To evaluate the acquisition of CPP in both experiments, data of the time spent in the drug-paired compartment were analyzed with a mixed ANOVA with a between subjects variable 'MDMA dose' with four levels (SAL, MDMA 5, 10, and 20), and a within subjects variable 'Days' with two levels (Pre-C and Post-C). Newman-Keuls tests were used to make post hoc comparisons. With the data of Post-C, a separate one-way ANOVA with a between factor (MDMA dose) was performed when the variable MDMA Dose resulted significant on Post-C day. During extinction and reinstatement tests, differences in time spent in the drug-paired compartment between Pre- $\mathrm{C}$ and each extinction session or reinstatement test were analyzed with a Student's $t$-test. Each monoamine or metabolite in each of the brain structures studied was analyzed using a two-way ANOVA with two between variables 'Schedule of Treatment' with two levels (Daily and Alternating) and 'MDMA Dose' with four levels (SAL, MDMA 5, 10 and 20).

\section{RESULTS}

\section{Experiment 1}

Effects of MDMA on acquisition, extinction and reinstatement of place preference using a two-session/day schedule during acquisition of place conditioning. The results obtained in Experiment 1 are represented in Figure 1. 


\section{Acquisition}

The ANOVA revealed a significant effect of the variable Days $(F(1,36)=4.830 ; P<0.0345)$. The variable MDMA Dose $(F(3,36)=0.736 ; P<0.5376)$ and the Interaction MDMA dose $\times$ days $(F(3,36)=1.224 ; P<0.315)$ were not significant.

\section{Extinction}

Animals treated with saline did not present CPP on Post-C days and nor did they exhibit CPP in the first extinction session. Conversely, although animals conditioned with $5 \mathrm{mg} / \mathrm{kg}$ of MDMA did not present CPP in Post-C, they exhibited a clear CPP when tested in the first extinction session performed a week after Post-C $(P<0.001$, significant difference with respect to Pre-C) and this CPP lasted 1 week more $(P<0.01)$. Similarly, in the first extinction session animals conditioned with 10 and $20 \mathrm{mg} / \mathrm{kg}$ showed CPP, which lasted for twelve weeks $(P<0.05)$ and 21 weeks more $(P<0.05)$, respectively.

\section{Reinstatement}

The dose of $2.5 \mathrm{mg} / \mathrm{kg}$ of MDMA did not produce reinstatement in animals conditioned with saline. In animals conditioned with 5,10 , or $20 \mathrm{mg} / \mathrm{kg}$ of MDMA, after confirmation of extinction, an injection with half of the dose used for conditioning $(2.5,5$ or $10 \mathrm{mg} / \mathrm{kg}$, respectively) also failed to produce reinstatement.

\section{Experiment 2}

Effects of MDMA on acquisition, extinction and reinstatement of place preference using an alternating day schedule during acquisition of place conditioning. The results obtained in Experiment 2 are represented in Figure 2.

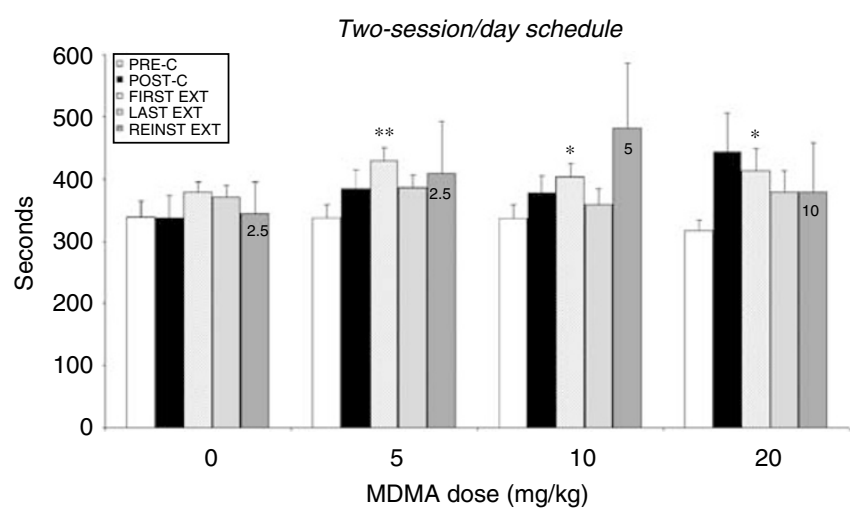

Figure I Acquisition, extinction and reinstatement of MDMA-induced CPP using a two-session/day schedule during the conditioning phase in four groups of animals $(n=10)$ : 0 , animals receiving saline in both compartments; 5,10 , and 20 , animals receiving 5,10 , or $20 \mathrm{mg} / \mathrm{kg}$ of MDMA in the drug-paired compartment. The bars represent the mean ( + SEM) time spent in the drug-paired compartment before conditioning sessions (white bars), after conditioning sessions (black bars), in the first extinction session (dashed bars), in the last extinction session (light gray bars) and in the reinstatement test (dark gray bars). Each reinstatement bar contains the dose of MDMA (mg/ $/ \mathrm{kg})$ used as priming. $* * P<0.01$, $* P<0.05$, significant difference in the time spent in Pre- $C$ vs Post- $C$ sessions or reinstatement tests.

\section{Acquisition}

The ANOVA revealed a significant effect of the variables MDMA dose $(F(3,53)=2.837 ; \quad P<0.0467)$ and days $(F(1,53)=44.581 ; P<0.0001)$ and the Interaction MDMA dose $\times$ days $(F(3,53)=8.021 ; P<0.0002)$. Simple effects of the interaction indicated that the effects of MDMA Dose was significant only in Post-C $(P<0.001)$ and the effects of days was significant in the groups receiving each dose of MDMA $(P<0.001)$. A separate ANOVA performed with the data of Post-C revealed a significant effect of MDMA dose $(F(3,53)=8.378 ; P<0.0001)$. Post hoc comparison demonstrated that animals treated with MDMA spent more time in the drug-paired compartment in comparison to animals receiving saline $(P<0.01)$.

\section{Extinction}

Animals treated with saline did not present CPP on Post-C days and nor in the first extinction session. Conversely, those treated with 5 or $20 \mathrm{mg} / \mathrm{kg}$ of MDMA showed CPP through four extinction sessions $(P<0.05)$, it disappearing in the fifth session (lack of significant differences with PreC). Animals treated with $10 \mathrm{mg} / \mathrm{kg}$ of MDMA presented CPP only in the first extinction session $(P<0.05)$ but not in the second.

\section{Reinstatement}

The dose of $10 \mathrm{mg} / \mathrm{kg}$ of MDMA did not produce the reinstatement of CPP in animals conditioned with saline. In those conditioned with $5 \mathrm{mg} / \mathrm{kg}$ of MDMA, after confirmation of extinction, the dose of $2.5 \mathrm{mg} / \mathrm{kg}$ of MDMA produced

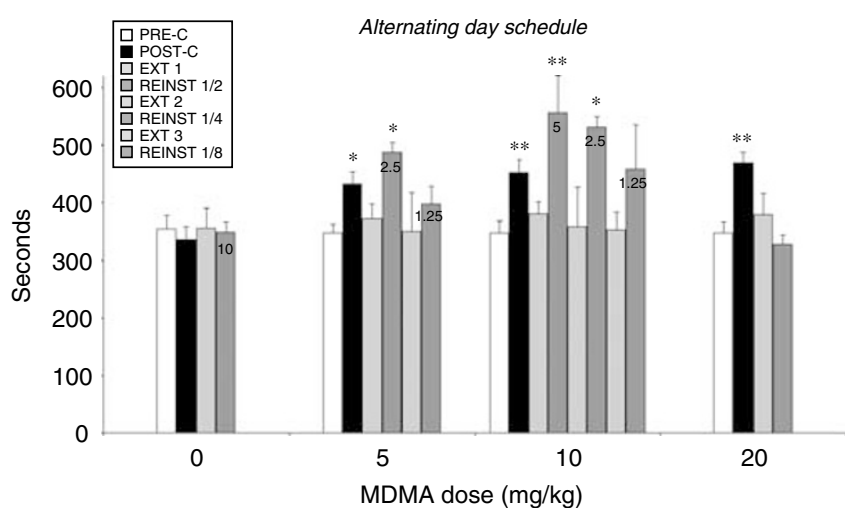

Figure 2 Acquisition, extinction and reinstatement of MDMA-induced CPP using an alternating day schedule during the conditioning phase in four groups of animals: 0 , animals receiving saline in both compartments $(n=14) ; 5,10$, and 20, animals receiving 5,10 , or $20 \mathrm{mg} / \mathrm{kg}$ of MDMA in the drug-paired compartment $(n=14,13,14$, respectively). The bars represent the mean $( \pm$ SEM) time spent in the drug-paired compartment before conditioning sessions (white bars), after conditioning sessions (black bars), in the last extinction session (light gray bars) and in the reinstatement test (dark gray bars) after a priming injection of MDMA at half of the dose used to induce CPP $(\mathrm{I} / 2)$. In those groups which presented reinstatement of CPP, after a new extinction, the priming effects of a dose corresponding to a quarter (1/4) and an eighth (1/8) of the dose used to induce CPP. Each reinstatement bar contains the dose of MDMA $(\mathrm{mg} / \mathrm{kg})$ used as priming. ${ }^{*} * P<0.01$, ${ }^{*} P<0.05$, significant difference in the time spent in Pre-C vs Post-C sessions or reinstatement tests. 
reinstatement $(P<0.05)$, which lasted 1 week $(P<0.05)$. After confirmation of a new extinction, the dose of $1.25 \mathrm{mg} /$ $\mathrm{kg}$ of MDMA did not produce reinstatement (approximately eight weeks after Post-C). In animals conditioned with $10 \mathrm{mg} / \mathrm{kg}$ of MDMA, after confirmation of extinction, the dose of $5 \mathrm{mg} / \mathrm{kg}$ of MDMA produced the reinstatement of CPP $(P<0.01)$, which lasted one week $(P<0.05)$. After confirmation of a new extinction, the dose of $2.5 \mathrm{mg} / \mathrm{kg}$ of MDMA again produced reinstatement $(P<0.05)$, approximately eight weeks after Post-C. After confirmation of a new extinction, the dose of $1.25 \mathrm{mg} / \mathrm{kg}$ of MDMA did not produce reinstatement (approximately seven weeks after Post-C). In animals conditioned with $20 \mathrm{mg} / \mathrm{kg}$ of MDMA, after confirmation of extinction, $10 \mathrm{mg} / \mathrm{kg}$ of MDMA did not produce the reinstatement of CPP, approximately five weeks after Post-C.

\section{Analysis of Biogenic Amines}

The results obtained are represented in Figures 3-6.

\section{Cortex}

A decrease in the amount of 5-HT was obtained in mice treated with the low dose of MDMA with the daily regimen and after received 10 or $20 \mathrm{mg} / \mathrm{kg}$ of MDMA with an alternating schedule. Irrespective of the regimen employed, after receiving $10 \mathrm{mg} / \mathrm{kg}$ of MDMA the amount of 5-HIAA was higher than in the other groups. Conversely, after receiving the highest dose of MDMA with an alternating regimen, the level of this metabolite was lower (Figure 3).

\section{Hippocampus}

Irrespective of the schedule employed, mice treated with the higher doses of MDMA presented a decrease in 5-HT and 5HIAA. In addition, the low dose decreased this metabolite only with the alternating schedule (Figure 4).

\section{Striatum}

5-HT was lower in animals treated with the daily regimen, there not being a significant decrease in those receiving MDMA on alternate days. The low and intermediate doses of MDMA decreased the amount of 5-HIAA (Figure 5). Administration of 5 or $10 \mathrm{mg} / \mathrm{kg}$ of MDMA decreased DA concentration in the mice treated with the daily regimen, as there were no differences between groups on the alternating regimen. The DOPAC level was higher in the animals treated with 10 or $20 \mathrm{mg} / \mathrm{kg}$ of MDMA with the daily regimen. Administration of MDMA decreased HVA concentration in comparison with the other two groups, except for the higher dose administered with the daily schedule (Figure 6).

\section{DISCUSSION}

The results obtained show that daily and alternating schedules of MDMA administration produced different behavioral and neurochemical effects. The main findings are that two different schedules of MDMA treatment yield different effects on CPP (as assessed by acquisition,
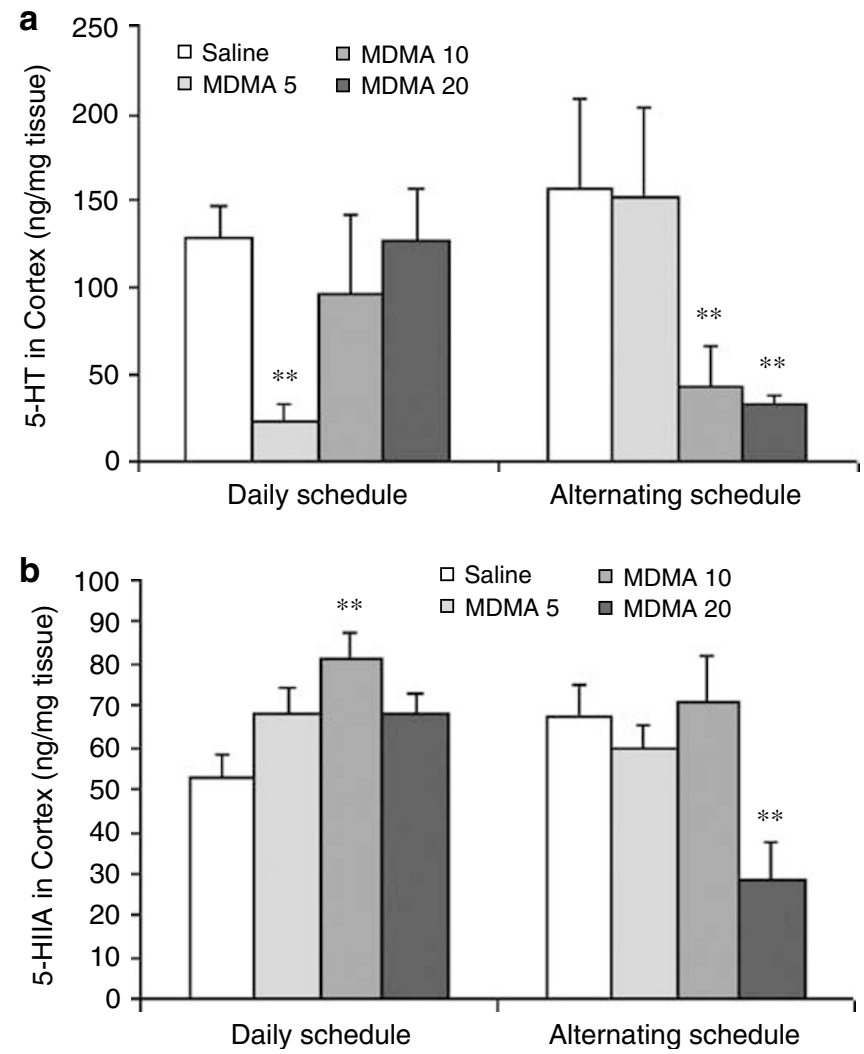

Figure 3 Effects of MDMA (5, 10, or $20 \mathrm{mg} / \mathrm{kg}$ ) on the concentrations of 5-HT (a) and 5-HIIA (b) in the cortex following daily or alternating schedule of administration. In the daily schedule, animals received four injections of the MDMA dose on 4 consecutive days and the levels of biogen amines were tested $24 \mathrm{~h}$ after the last injection. In the alternating schedule, animals received four injections of the MDMA dose each $48 \mathrm{~h}$ through 8 days and amine levels were evaluated $48 \mathrm{~h}$ after the last injection. ${ }^{*} * P<0.01$, significant difference with respect to saline group.

extinction and reinstatement) and that the MDMA priming produces a reinstatement of MDMA-induced CPP. Overall, our results confirm the rewarding effects of MDMA and demonstrate that this drug can produce long-term effects which influence the vulnerability of the animals to relapse after withdrawal.

\section{MDMA-Induced Reinstatement of CPP}

The most important and original results observed in the present study are the long-term effects of MDMA on reward processes, as the reinstating effects of MDMA exposure after extinction have not been evaluated previously. Here, using the place conditioning paradigm, we observed that reexposure to MDMA after extinction of CPP reinstates its conditioned rewarding effects. The reinstatement of previously extinguished CPP is observed with half of the dose used during conditioning in animals which demonstrated CPP after the low and medium dose (priming of 2.5 and $5 \mathrm{mg} / \mathrm{kg}$ of MDMA, respectively). Moreover, the animals conditioned with the medium dose of MDMA $(10 \mathrm{mg} / \mathrm{kg})$ also present reinstatement after the re-exposure to a quarter of the dose previously used during conditioning $(2.5 \mathrm{mg} / \mathrm{kg})$ after a new extinction of reinstatement induced by $5 \mathrm{mg} / \mathrm{kg}$. Conversely, animals which received the high dose of MDMA 

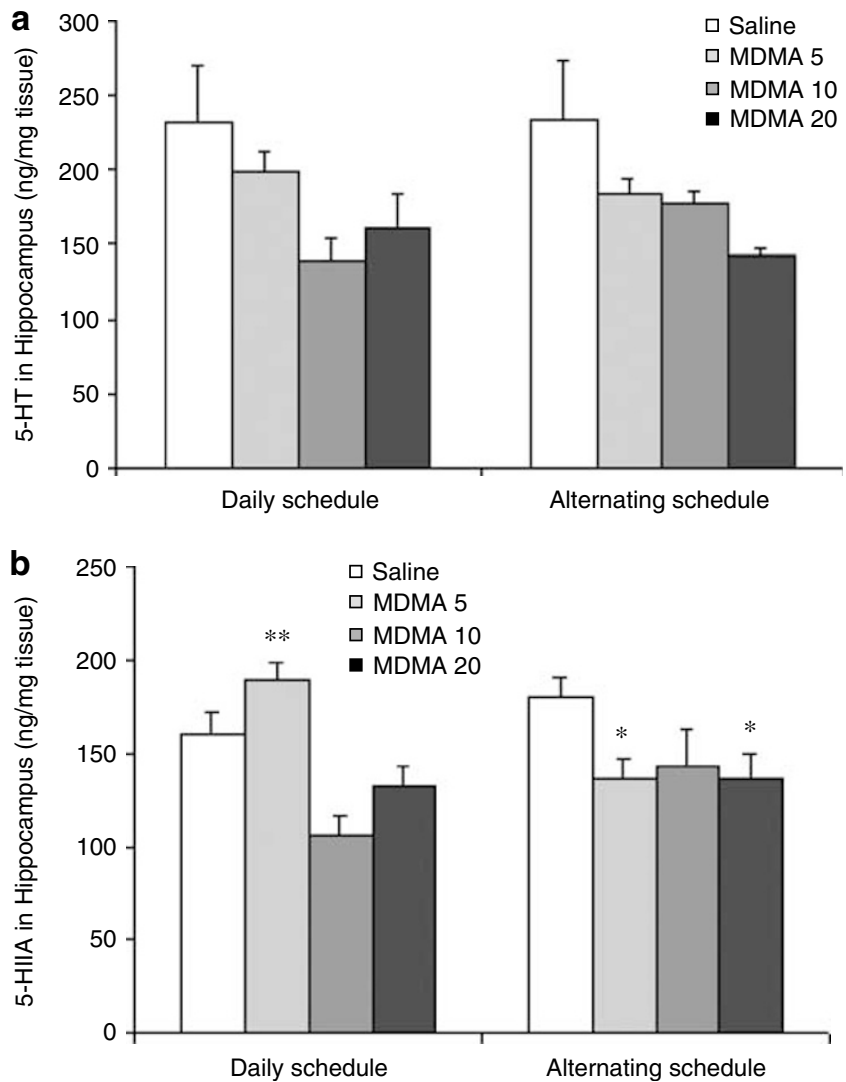

Figure 4 Effects of MDMA (5, 10, or $20 \mathrm{mg} / \mathrm{kg}$ ) on the concentrations of 5-HT (a) and 5-HIIA (b) in the hippocampus following daily or alternating schedule of administration. In the daily schedule, animals received four injections of the MDMA dose on four consecutive days and the levels of biogen amines were tested $24 \mathrm{~h}$ after the last injection. In the alternating schedule, animals received 4 injections of the MDMA dose each $48 \mathrm{~h}$ through 8 days and amine levels were evaluated $48 \mathrm{~h}$ after the last injection. ** $P<0.0$ I, significant difference with respect to saline group.

during conditioning do not present reinstatement after a priming dose of $10 \mathrm{mg} / \mathrm{kg}$. Thus, although the different doses produced a similar degree of CPP in all groups of animals, their susceptibility to the reinstatement induced by MDMA re-exposure may vary, it being greater in those conditioned with $10 \mathrm{mg} / \mathrm{kg}$. A possible explanation for the lack of effects of the high dose on reinstatement can be focused on the development of sensitization after MDMA pre-exposure. During conditioning, animals were exposed to MDMA and, after a period of several weeks without injections (extinction), the effects of the drug were tested again in the reinstatement tests. If pre-exposure to MDMA could induce an increase in its effects (sensitization), the dose-effect curve would be shifted to the left and thus, the dose of 2.5 and 5 could induce more rewarding effects than $10 \mathrm{mg} / \mathrm{kg}$, which may induce non-rewarding or even aversive effects in pre-exposed mice, interfering with the reinstatement process. Using the self-administration procedure, it has been observed that MDMA exhibited an inverted $U$ dose-effect curve in mice, which were more motivated to obtain lower rather than higher doses of MDMA. Although no overt changes in the pattern or the rate of responding were observed during 15 days of MDMA self-administration, suggesting the lack of acute tolerance or
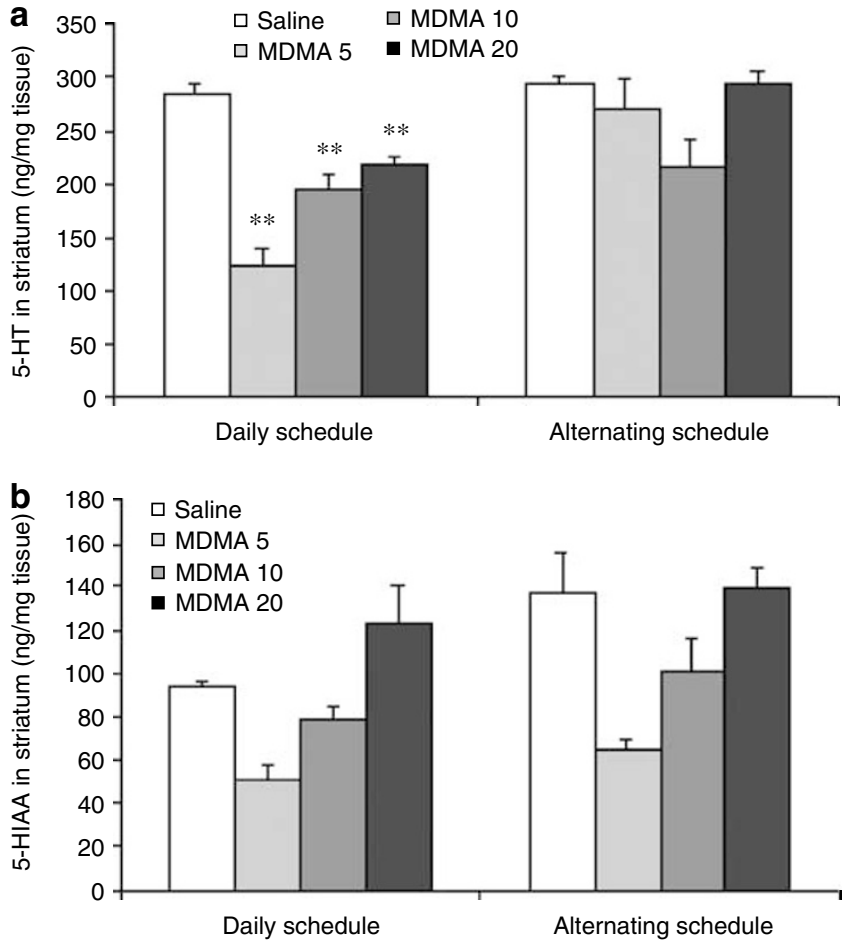

Figure 5 Effects of MDMA (5, 10, or $20 \mathrm{mg} / \mathrm{kg}$ ) on the concentrations of 5-HT (a) and 5-HIIA (b) in the striatum following daily or alternating schedule of administration. In the daily schedule, animals received 4 injections of the MDMA dose on four consecutive days and the levels of biogen amines were tested $24 \mathrm{~h}$ after the last injection. In the alternating schedule, animals received four injections of the MDMA dose each $48 \mathrm{~h}$ through 8 days and amine levels were evaluated $48 \mathrm{~h}$ after the last injection. *** $<0.0$ I, significant difference with respect to saline group.

sensitization to its reinforcing properties, it is possible that sensitization only emerges after a non-drug interval (Trigo et al, 2006). In accord with this hypothesis, in one study evaluating the motor effects of MDMA in rats, it was observed that dose-dependent increases were produced in motor activity that remained constant through six consecutive daily injections but after 5 or 25 days of washout, an increase in locomotion was observed, which expresses behavioral sensitization (Modi et al, 2006). Similarly, we found that a low dose MDMA injection, after an interval of 2 or 5 weeks from the last drug administration during conditioning, produces a clear reinstatement of $\mathrm{CPP}$, which can be even greater than that observed during Post-C.

The reinstating effects of MDMA may probably be affected by the interval elapsed between the conditioning (performed during adolescence) and the tests of reinstatement, which were performed between PN 56 and 77 in animals conditioned with the alternating schedule but between PN 59 and 199 in animals conditioned with the daily schedule, however, the results obtained argue against this hypothesis. Although both groups of animals conditioned with $5 \mathrm{mg} / \mathrm{kg}$ performed the reinstatement test at similar PN days (59 or 77 in daily or alternating, respectively), the priming dose of $2.5 \mathrm{mg} / \mathrm{kg}$ only reinstates CPP in animals conditioned using the alternating day schedule. Conversely, the dose of $10 \mathrm{mg} / \mathrm{kg}$ of MDMA does not reinstate CPP in any group conditioned with $20 \mathrm{mg} / \mathrm{kg}$, irrespective of the time at which reinstatement tests were 
$\square$ Saline $\square$ MDMA 5

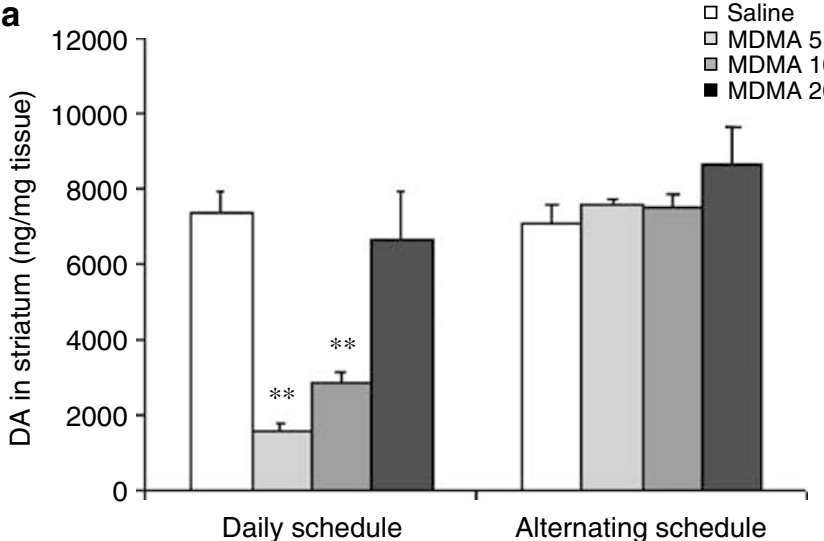

b
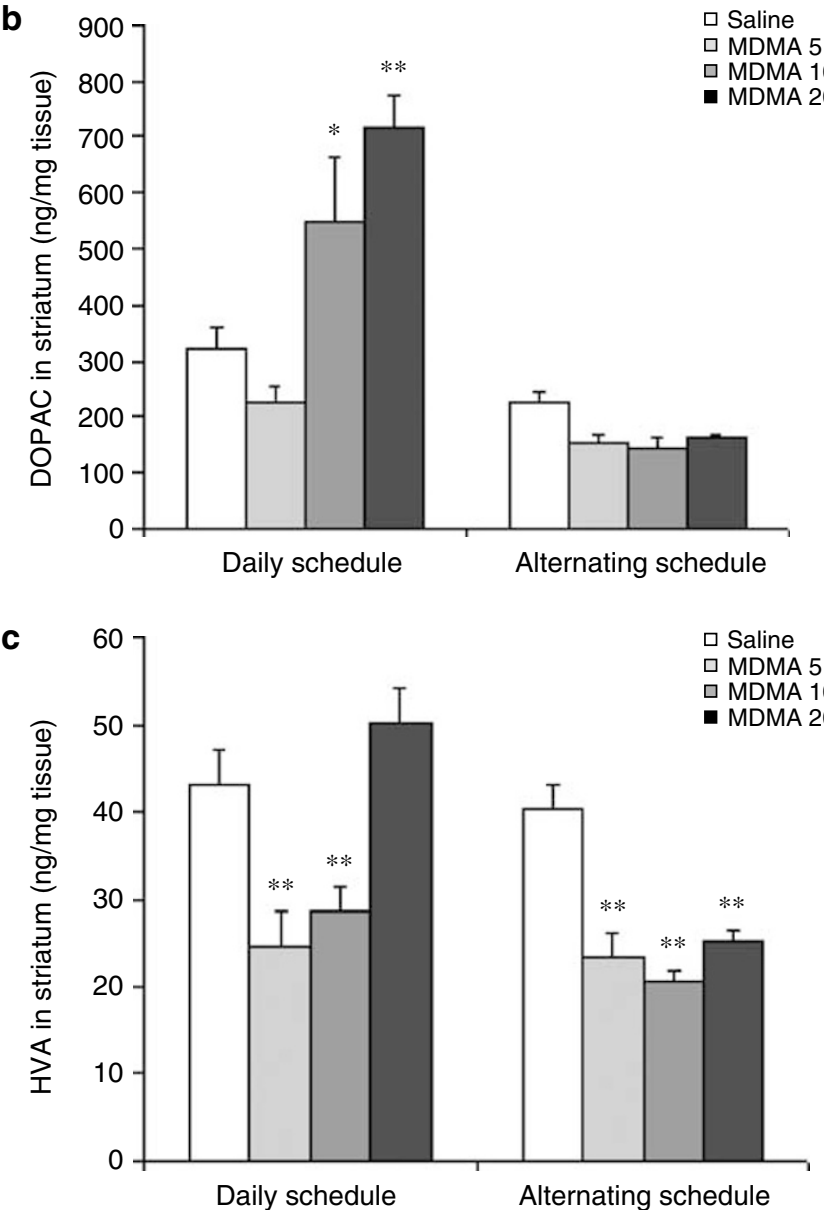

Figure 6 Effects of MDMA (5, 10, or $20 \mathrm{mg} / \mathrm{kg}$ ) on the concentrations of DA (a), DOPAC (b), and HVA (c) in the striatum following daily or alternating schedule of administration. In the daily schedule, animals received four injections of the MDMA dose on four consecutive days and the levels of biogen amines were tested $24 \mathrm{~h}$ after the last injection. In the alternating schedule, animals received 4 injections of the MDMA dose each $48 \mathrm{~h}$ through 8 days and amine levels were evaluated $48 \mathrm{~h}$ after the last injection. $* * P<0.01, * P<0.05$, significant difference with respect to saline group.

performed (PN 199 vs PN 77). Finally, although the test of reinstatement is performed at very different PN days (164 vs 56 ), in both groups conditioned with $10 \mathrm{mg} / \mathrm{kg}$, the priming dose of $5 \mathrm{mg} / \mathrm{kg}$ induces an increase in the time spent in the drug-paired compartment (even higher than in Post-C), although this effect is only significant in animals conditioned using an alternating day schedule. The lack of significant differences in those conditioned using the twosession/day schedule could be due to the great variability between mice in response to MDMA priming (see the wide SEM in Figure 1): some animals clearly increase the time spent in the drug-paired compartment but others decrease it. Thus, the temporal interval between conditioning and test of reinstatement does not seem to be responsible for the different susceptibility to reinstatement observed in animals conditioned with a two/session day schedule or an alternating day schedule. An explanation focused on the type of conditioning acquired by mice in both types of schedules is more plausible. Intermittent MDMA could have more ability to induce sensitization and modify brain reward pathways than daily treatment, rendering animals more susceptible to reinstatement after re-exposure to the drug received during conditioning.

\section{Effects of Daily and Alternating MDMA Administration on the Acquisition and Extinction of CPP}

In the present study, we have used two different protocols for the acquisition of place conditioning due to the fact that a review of the literature on the effects of MDMA on CPP indicates that they can vary as a function of several factors, such as housing of the animals or procedure of CPP. Four daily consecutive pairings of MDMA with the corresponding drug-paired compartment does not significantly increase the time spent in this compartment in the Post-C session with respect to that spent on the Pre-C day, although there is a tendency to induce CPP with the high dose of MDMA. The lack of significant differences in this group are probably due to the great variability in the response of the animals: some showing a great change in time spent in the MDMA-paired compartment $(>540 \mathrm{~s}$ ) but some showing even a decrease $(<223 \mathrm{~s})$. When animals are tested one week after to verify the lack of CPP, surprisingly, we observed that MDMA-conditioned animals present a clear CPP (see Figure 1, bar of First Extinction session). As we have previously observed with other drugs of abuse (Maldonado et al, 2006; Ribeiro Do Couto et al, 2005a), the duration of MDMA-induced CPP is dose-dependent: animals presented CPP 3, 13 and 22 weeks after conditioning with the low-, medium-, and high-dose, respectively. These results indicate that animals have acquired a longlasting CPP, although they do not express it 1 day after the last conditioning session. A possible explanation for these effects could be focused on the fact that MDMA may produce a transient depletion of one or several neurotransmitters involved in the expression of CPP, such as $5-\mathrm{HT}$ or DA. On the other hand, the phenomenon of 'incubation' of responding to reward cues (Grimm et al, 2001; Lu et al, 2004) could also contribute to the increased CPP over time following the completion of training, it becoming more evident 1 or several weeks after the last conditioning session (extinction sessions) than only 1 day after (Post-C).

The effects of MDMA on CPP have always been evaluated using a schedule of alternating days. With this model, in agreement with previous studies with adult mice (Robledo et al, 2004a, b; Salzmann et al, 2003), we have observed that 
all doses of MDMA induced a clear CPP on Post-C day, although the duration of this CPP is not dose-dependent. Animals treated with low and high doses present CPP up to a maximum of 4 weeks, whereas those receiving the medium dose only exhibited CPP for 1 week after conditioning. Thus, besides differences in the acquisition, the duration of CPP clearly differs depending on the schedule used. With the two-session/day schedule, the extinction sessions extended from PN 41 to PN 195, as the duration of CPP is very long; whereas with the alternating day schedule, the extinction sessions extended from PN 45 to PN 73, as CPP lasts a few weeks. It is not clear whether the different protocols used to induce conditioning, daily being more intensive (four conditioning sessions in 4 days) than alternating (four conditioning sessions in 8 days), could explain these differences.

\section{Effects of Daily and Alternating MDMA Administration on Biogenic Amines}

With the objective of finding the neurochemical correlates of the effects observed in the acquisition of CPP, we evaluated the levels of 5-HT, DA and their metabolites in brain cortex, hippocampus, and striatum of mice treated with a daily or an alternating schedule of MDMA administration. Daily MDMA produces a decrease in 5-HT in the cortex with the low dose and in the striatum with all doses (striatal 5-HT loss of 56, 32, and 23\% for the low-, medium-, and high dose, respectively). There is also a decrease in DA after the low and medium MDMA doses (DA loss of 74 and $52 \%$, respectively). The lack of dosedependence in the effect of MDMA on 5-HT and DA levels may be due to the fact that the animals treated with the highest dose were under the stimulating effect of the drug (as the neurotransmitter levels are evaluated only $24 \mathrm{~h}$ after the last administration). It is important to note that the pattern of 5-HT and DA concentrations is similar in the striatum and cortex (only 5-HT): greater decreases with the lower doses. It is possible that with repeated daily high dosage the stimulant effects of MDMA on DA release accumulates. Using in vivo microdialysis, it has been confirmed that the extracellular DA concentration in the mouse striatum increased after a single dose of MDMA (Camarero et al, 2002; Colado et al, 2001; Reveron et al, $2005)$ and that this rise was magnified and sustained by subsequent doses (Camarero et al, 2002; Colado et al, 2001). The alternating schedule of MDMA administration produces a dose-dependent decrease in cortical 5-HT without changes in striatal 5-HT or DA. In the hippocampus, 5-HT decreased in a dose-dependent way independently of the schedule used.

As commented previously, the apparent absence of CPP in animals conditioned with the two-session/day schedule could be due to the depletion of a neurotransmitter after daily MDMA administration. Biochemical analysis demonstrated a decrease in DA and 5-HT in the striatum that could be related to the lack of CPP. In fact, animals receiving the high dose of MDMA that present a lower decrease in DA show a greater increase in the time spent in the drug-paired compartment, whereas this is not the case in animals receiving low and medium doses that present a clear reduction in DA. When this drug is administered at 48-h intervals, these possible impairing effects on neurotransmission are prevented, as the neurotransmitters are within their normal levels that correlate with a clear expression of CPP in animals conditioned with the alternating schedule.

The CPP paradigm, a model of context-conditioned drug reward, is especially relevant for addiction research because contextual stimuli (acting as secondary reinforcers) can induce craving that might finally lead to relapse (Childress et al, 1999). As drugs that have rewarding properties are also considered to have a higher probability of dependence and abuse liability, the ability of MDMA to produce CPP observed in the present study may be predictive of such properties. Moreover, the long-term effects of MDMA on the susceptibility of the animals to the reinstatement of CPP induced by the re-exposure to this drug after extinction support the idea that MDMA exposure is capable of modifying the neural substrates of reward, making the animal's brain more vulnerable to addiction.

\section{ACKNOWLEDGEMENTS}

This work was supported by the following grants:

Ministerio de Sanidad y Consumo, Instituto de Salud 'Carlos III' (FIS), Redes Temáticas de Investigación Cooperativa (G03/005) and Proyectos de Investigación (PI052165). Ministerio de Educación y Ciencia, Dirección General de Investigación and FEDER (SEJ2005-00316/PSIC) (Spain). Conselleria de Sanitat, Agencia Valenciana de Salud. Dirección General de Drogodependencias (FEPAD) and Conselleria d' empresa, Universitat i Ciencia, Proyectos I + D (GV04B46, GV06/355, ACOMP06/211), Generalitat Valenciana (Spain). Bruno Ribeiro Do Couto was supported by grant SFRH/BD/4559/2001 of the Fundação Para a Ciência e a Tecnologia, Ministério da Ciểncia e da Tecnologia (Portugal).

\section{REFERENCES}

Acquas E, Marrocu P, Pisanu A, Cadoni C, Zernig G, Saria A et al (2001). Intravenous administration of ecstasy (3,4-methylenedioxymethamphetamine) enhances cortical and striatal acetylcholine release in vivo. Eur J Pharmacol 418: 207-211.

Beardsley PM, Balster RL, Harris LS (1986). Self-administration of methylenedioxymethamphetamine (MDMA) by rhesus monkeys. Drug Alcohol Depend 18: 149-157.

Bilsky EJ, Reid LD (1991). MDL72222, a serotonin 5-HT3 receptor antagonist, blocks MDMA's ability to establish a conditioned place preference. Pharmacol Biochem Behav 39: 509-512.

Bilsky EJ, Hui Y, Hubbell CL, Reid LD (1990). Methylenedioxymethamphetamine's capacity to establish place preferences and modify intake of an alcoholic beverage. Pharmacol Biochem Behav 37: 633-638.

Bilsky EJ, Hubell CL, Delconte JD, Reid LD (1991). MDMA produces a conditioned place preference and elicits ejaculation in male rats: a modulatory role for the endogenous opioids. Pharmacol Biochem Behav 40: 443-447.

Bilsky EJ, Montegut MJ, Nichols ML, Reid LD (1998). CGS 10746B, a novel dopamine release inhibitor, blocks the establishment of cocaine and MDMA conditioned place preferences. Pharmacol Biochem Behav 59: 215-220.

Boot BP, Mechan AO, McCann UD, Ricaurte GA (2002). MDMA- and p-chlorophenylalanine-induced reduction in 5-HT 
concentrations: effects on serotonin transporter densities. Eur J Pharmacol 453: 239-244.

Braida D, Sala M (2002). Role of the endocannabinoid system in MDMA intracerebral self-administration in rats. Br J Pharmacol 136: 1089-1092.

Braida D, Iosuè S, Pegorini S, Sala M (2005). 3,4 Methylenedioxymethamphetamine-induced conditioned place preference (CPP) is mediated by the endocannabinoid system. Pharmacol Res 51: 177-182.

Cadoni C, Solinas M, Pisanu A, Zernig G, Acquas E, Di Chiara G (2005). Effects of 3,4-methylendioxymethamphetamine (MDMA, 'ecstasy') on dopamine transmission in the nucleus accumbens shell and core. Brain Res 1055: 143-148.

Camarero J, Sanchez V, O'Shea E, Green AR, Colado MI (2002). Studies, using in vivo microdialysis, on the effect of the dopamine uptake inhibitor GBR 12909 on 3,4-methylenedioxymethamphetamine ('ecstasy')-induced dopamine release and free radical formation in the mouse striatum. J Neurochem 81: 961-972.

Carroll ME, Comer SD (1996). Animal models of relapse. Exp Clin Psychopharmacol 4: 11-18.

Colado MI, Camarero J, Mechan AO, Sanchez V, Esteban B, Elliott JM et al (2001). A study of the mechanisms involved in the neurotoxic action of 3,4-methylenedioxymethamphetamine (MDMA, 'ecstasy') on dopamine neurons in mouse brain. $\mathrm{Br} \mathrm{J}$ Pharmacol 134: 1711-1723.

Colado MI, O'Shea E, Green AR (2004). Acute and long-term effects of MDMA on cerebral dopamine biochemistry and function. Psychopharmacology 173: 249-263.

Cole JC, Sumnall HR (2003). The pre-clinical behavioural pharmacology of 3,4-methylenedioxymethamphetamine (MDMA). Neurosci Biobehav Rev 27: 199-217.

Cole JC, Sumnall HR, O'Shea E, Marsden CA (2003). Effects of MDMA exposure on the conditioned place preference produced by other drugs of abuse. Psychopharmacology 166: 383-390.

Cornish JL, Shahnawaz Z, Thompson MR, Wong S, Morley KC, Hunt GE et al (2003). Heat increases 3,4-methylenedioxymethamphetamine self-administration and social effects in rats. Eur J Pharmacol 482: 339-341.

Childress AR, Mozley PD, McElgin W, Fitzgerald J, Reivich M, ÓBrien CP (1999). Limbic activation during cue-induced cocaine craving. Am J Psychiatry 156: 11-18.

Daniela E, Brennan K, Gittings D, Hely L, Schenk S (2004). Effect of SCH 23390 on (+/-)-3,4-methylenedioxymethamphetamine hyperactivity and self-administration in rats. Pharmacol Biochem Behav 77: 745-750.

Escobedo I, O'Shea E, Orio L, Sanchez V, Segura M, de la Torre R et al (2005). A comparative study on the acute and long-term effects of MDMA and 3,4-dihydroxymethamphetamine (HHMA) on brain monoamine levels after i.p. or striatal administration in mice. Br J Pharmacol 144: 231-241.

Fantegrossi WE, Ullrich T, Rice KC, Woods JH, Winger G (2002). 3,4-Methylenedioxymethamphetamine (MDMA, 'ecstasy') and its stereoisomers as reinforcers in rhesus monkeys: serotonergic involvement. Psychopharmacology 161: 356-364.

Fantegrossi WE, Woolverton WL, Kilbourn M, Sherman P, Yuan J, Hatzidimitriou G et al (2004). Behavioral and neurochemical consequences of long-term intravenous self-administration of MDMA and its enantiomers by rhesus monkeys. Neuropsychopharmacology 29: 1270-1281.

Gough B, Ali SF, Slikker W, Holson RR (1991). Acute effects of 3,4methylenedioxymethamphetamine (MDMA) on monoamines in rat caudate. Pharmacol Biochem Behav 39: 619-623.

Grimm JW, Hope BT, Wise RA, Shaham Y (2001). Incubation of cocaine craving after withdrawal. Nature 412: 141-142.

Herzig V, Capuani EM, Kovar KA, Schmidt WJ (2005). Effects of MPEP on expression of food-, MDMA- or amphetamineconditioned place preference in rats. Addict Biol 10: 243-249.
Hiramatsu M, Cho AK (1990). Enantiomeric differences in the effects of 3,4-methylenedioxymethamphetamine on extracellular monoamines and metabolites in the striatum of freely-moving rats: an in vivo microdialysis study. Neuropharmacology 29: 269-275.

Kankaanpaa A, Meririnne E, Lillsunde P, Seppala T (1998). The acute effects of amphetamine derivatives on extracellular serotonin and dopamine levels in rat nucleus accumbens. Pharmacol Biochem Behav 59: 1003-1009.

Koch S, Galloway MP (1997). MDMA induced dopamine release in vivo: role of endogenous serotonin. J Neural Transm 104: 135-146.

Lamb R, Griffiths R (1987). Self-injections of d-3,4-methylenedioxymethamphetamine (MDMA) in the baboon. Psychopharmacology 91: 268-272.

Li S-M, Ren Y-H, Zheng J-W (2002). Effect of 7-nitroindazole on drug-priming reinstatement of $\mathrm{D}$-methamphetamine-induced conditioned place preference. Eur J Pharmacol 443: 205-206.

Lile JA, Ross JT, Nader MA (2005). A comparison of the reinforcing efficacy of 3,4-methylenedioxymethamphetamine (MDMA, 'ecstasy') with cocaine in rhesus monkeys. Drug Alcohol Depend 78: 135-140.

Lu L, Grimm JW, Dempsey J, Shaham Y (2004). Cocaine seeking over extended withdrawal periods in rats: different time courses of responding induced by cocaine cues versus cocaine priming over the first 6 months. Psychopharmacology 176: 101-108.

Maldonado C, Rodriguez-Arias M, Castillo A, Aguilar MA, Miñarro $\mathrm{J}$ (2006). Gamma-hydroxybutyric acid affects the acquisition and reinstatement of cocaine-induced conditioned place preference in mice. Behav Pharmacol 17: 119-131.

Manzanedo C, Aguilar MA, Rodríguez-Arias M, Miñarro J (2001). Effects of dopamine antagonists with different receptor blockade profiles on morphine-induced place preference in male mice. Behav Brain Res 121: 189-197.

Marona-Lewicka D, Rhee G-S, Sprague JE, Nichols DE (1996). Reinforcing effects of certain serotonin-releasing amphetamine derivatives. Pharmacol Biochem Behav 53: 99-105.

McGregor IS, Clemens KJ, van der Plass G, Li KM, Hunt GE, Chen F et al (2003). Increased anxiety 3 months after brief exposure to MDMA ('ecstasy') in rats: association with altered 5-HT transporter and receptor density. Neuropsychopharmacology $\mathbf{2 8}$ 1472-1484

Meyer A, Mayerhofer A, Kovar K-A, Schmidt WJ (2002). Rewarding effects of the optical isomers of 3,4-methylenedioxy-methylamphetamine ('Ecstasy') and 3,4-methylenedioxyethylamphetamine ('Eve') measured by conditioned place preference in rats. Neurosci Lett 330: 280-284.

Modi GM, Yang PB, Swann AC, Dafny N (2006). Chronic exposure to MDMA (Ecstasy) elicits behavioral sensitization in rats but fails to induce cross-sensitization to other psychostimulants. Behav Brain Funct 2: 1.

Nair SG, Gudelsky GA (2006). 3,4-Methylenedioxymethamphetamine enhances the release of acetylcholine in the prefrontal cortex and dorsal hippocampus of the rat. Psychopharmacology 184: 182-189.

Nichols DE (1986). Differences between the mechanism of action of MDMA, MBDB, and the classic hallucinogens. Identification of a new therapeutic class: entactogens. J Psychoactive Drugs 18 305-313.

O’Brien CP (1997). A range of research-based pharmacotherapies for addiction. Science 278: 66-70.

O'Shea E, Escobedo J, Orio L, Sanchez V, Navarro M, Green AR et al (2005). Elevation of ambient room temperature has differential effects on MDMA-induced 5-HT and dopamine release in striatum and nucleus accumbens of rats. Neuropsychopharmacology 30: 1312-1323.

Reveron ME, Monks TJ, Duvauchelle CL (2005). Age-dependent (+)MDMA-mediated neurotoxicity in mice. Neurotoxicology 26 $1031-1040$ 
Ribeiro Do Couto B, Aguilar MA, Rodriguez-Arias M, Miñarro J (2005a). Long-lasting rewarding effects of morphine induced by drug primings. Brain Res 1050: 53-63.

Ribeiro Do Couto B, Aguilar MA, Manzanedo C, Rodriguez-Arias M, Miñarro J (2005b). NMDA glutamate but not dopamine antagonists blocks drug-induced reinstatement of morphine place preference. Brain Res Bull 64: 493-503.

Ribeiro Do Couto B, Aguilar MA, Manzanedo C, Rodriguez-Arias M, Armario A, Miñarro J (2006). Social stress is as effective as physical stress in reinstating morphine-induced place preference in mice. Psychopharmacology 185: 459-470.

Ricaurte G, Bryan G, Strauss L, Seiden L, Schuster C (1985). Hallucinogenic amphetamine selectively destroys brain serotonin nerve terminals. Science 229: 986-988.

Robledo P, Balerio B, Berrendero F, Maldonado R (2004a). Study of the behavioural responses related to the potential addictive properties of MDMA in mice. Naunyn-Schmiedeberg's Arch Pharmacol 369: 338-349.

Robledo P, Mendizabal V, Ortuño J, de la Torre R, Kieffer BL, Maldonado R (2004b). The rewarding properties of MDMA are preserved in mice lacking $\mathrm{m}$-opioid receptors. Eur J Neurosci 20: 853-858.

Salzmann J, Marie-claire C, Le Guen S, Roques BP, Noble F (2003). Importance of ERK activation in behavioral and biochemical effects induced by MDMA in mice. Br J Pharmacol 140: 831-838.

Schechter MD (1991). Effect of MDMA neurotoxicity upon its conditioned place preference and discrimination. Pharmacol Biochem Behav 38: 539-544.
Schenk S, Gittings D, Johnstone M, Daniela E (2003). Development, maintenance and temporal pattern of self-administration maintained by ecstasy (MDMA) in rats. Psychopharmacology 169: 21-27.

Schmidt CJ, Levin JA, Lovenberg W (1987). In vitro and in vivo neurochemical effects of methylenedioxymethamphetamine on striatal monoaminergic systems in the rat brain. Biochem Pharmacol 36: 747-755.

Shaham Y, Shalev U, Lu L, de Wit H, Stewart J (2003). The reinstatement model of drug relapse: history, methodology and major findings. Psychopharmacology 168: 3-20.

Shalev U, Grimm JW, Shaham Y (2002). Neurobiology of relapse to heroin and cocaine seeking: a review. Pharmacol Rev 54: 1-42.

Stone DM, Johnson M, Hanson GR, Gibb JW (1987). A comparison of the neurotoxic potential of methylenedioxyamphetamine (MDA) and its $N$-methylated and $N$-ethylated derivatives. Eur $\mathrm{J}$ Pharmacol 134: 245-248.

Trigo JM, Panayi F, Soria G, Maldonado R, Robledo P (2006). A reliable model of intravenous MDMA self-administration in naive mice. Psychopharmacology 184: 212-220.

Weiss F (2005). Neurobiology of craving, conditioned reward and relapse. Current Opinion Pharmacol 5: 9-19.

White SR, Duffy P, Kalivas PW (1994). Methylenedioxymethamphetamine depresses glutamate-evoked neuronal firing and increases extracellular levels of dopamine and serotonin in the nucleus accumbens in vivo. Neuroscience 62: 41-50.

Yamamoto BK, Spanos LJ (1988). The acute effects of methylenedioxy-methamphetamine on dopamine release in the awakebehaving rat. Eur J Pharmacol 148: 195-203. 